\title{
Estudo da correlação do posicionamento dos incisivos superiores e inferiores com a relação ântero-posterior das bases ósseas
}

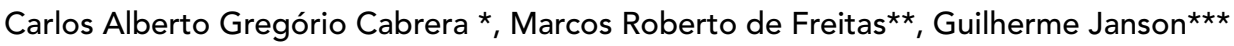

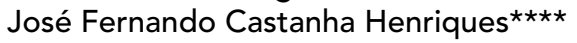

\begin{abstract}
Resumo
Objetivos: estudou-se a correlação quanto ao comportamento das bases ósseas através da avaliação Wits e as variações aceitáveis quanto às inclinações vestíbulo-linguais dos incisivos centrais superiores por meio de métodos específicos e distintos para as avaliações cefalométricas e em modelos em gesso. Metodologia: foram utilizadas telerradiografias em norma lateral e modelos em gesso de 57 jovens brasileiros, sendo 26 do gênero masculino e 31 do feminino, com idades de 12 anos e 9 meses a 20 anos e 11 meses, tratados ortodonticamente através de aparelhos Straight Wire - padrão, apresentando as seis chaves para a oclusão perfeita preconizada por Andrews. Resultados: para a avaliação Wits, quanto ao relacionamento entre as bases ósseas, o valor normativo encontrado foi de $-2,26 \mathrm{~mm}$ e desvio padrão de $1,83 \mathrm{~mm}$, sem dimorfismo sexual. Para as aferições cefalométricas, os valores das inclinações dos incisivos superiores apresentaram média de $+13,35^{\circ}$ e os inferiores de $+5,14^{\circ}$. Nas aferições em modelos, o valor padrão médio encontrado para as inclinações dos incisivos centrais superiores foi de $+7,96^{\circ}$ e para os inferiores de $+5,03^{\circ}$. Conclusão: na análise dos resultados foi possível constatar haver uma correlação significante entre o comportamento da variação das bases ósseas e as inclinações dos incisivos centrais superiores e inferiores.
\end{abstract}

Palavras-chave: Avaliação Wits. Incisivo. Oclusão normal. Cefalometria.

\section{INTRODUÇÃO}

Admite-se que, fisicamente, a incompatibilidade em acomodar um grande volume de massa dentária em um restrito local disponível de osso inviabiliza a disposição harmoniosa dos elementos dentários inferiores na mandíbula, como os superiores na maxila. Utilizando recursos terapêuticos, o ortodontista pode alterar o perímetro dos arcos

* Parte da dissertação apresentada à Faculdade de Odontologia de Bauru-USP, para obtenção do título de mestre em Ortodontia

* Doutorando em Ortodontia pela Universidade de São Paulo-USP/Bauru, Mestre em Ortodontia pela Universidade de São Paulo-USP/Bauru e Universidade Estadual de Londrina-UEL.

** Professor Associado de Ortodontia da Faculdade de Odontologia de Bauru da Universidade de São Paulo-FOB-USP;

*** Professor Associado da Disciplina de Ortodontia da Faculdade de Odontologia de Bauru - USP.

*** Professor titular do Departamento de Odontopediatria e Ortodontia e Saúde Coletiva da Faculdade de Odontologia de Bauru- USP; Coordenador dos Cursos de Pós-graduação em Ortodontia, ao nível de Doutorado e Especialização da Faculdade de Odontologia de Bauru. 
dentários reduzindo-os por meio de extrações ou desgastes dentários, expandindo-os, ou por vestibularização dos dentes. Como os ápices radiculares mantêm-se relativamente estáveis, a expansão ou redução do perímetro das arcadas dentárias ocorre por inclinações das coroas por vestibular ou lingual, respectivamente. Os elementos dentários posteriores, referenciados aqui como pré-molar e molares, tem seu equilíbrio vertical ditado pelo antagonismo da oclusão, enquanto as posições vestíbulo-linguais equilibram-se pelas ações externas da musculatura do bucinador e masseter, e internamente pela língua. Já anteriormente, os caninos, incisivos laterais e centrais possuem um equilíbrio vestíbulo-lingual limitado, devido à musculatura anterior dos orbiculares dos lábios ser dividida em superior e inferior e raramente mantida ocluída, desobstruindo assim a contenção externamente.

Para se compatibilizar os arcos dentários em uma oclusão perfeita, por vezes decisões difíceis devem ser tomadas, se por um lado as extrações serão requeridas para compatibilizar os arcos e favorecer a função, por outro poderão acarretar prejuízos ao perfil facial promovido pelo recuo dos lábios e conseqüente destaque do nariz quando da lingüalização dos incisivos centrais.

Diante da insegurança em decidir pela extração ou não, e da limitada possibilidade em prever o benefício ou prejuízo estético que possa acarretar no perfil mole do paciente, este estudo procura determinar quais os limites aceitáveis quanto à quantidade de vestibularização ou línguo-versão que se pode implementar nos incisivos superiores e inferiores, quando as bases ósseas estiverem bem relacionadas ou se vislumbra a possibilidade de conseguir esta tão ambicionada relação.

Mesmo reconhecendo que as seis chaves para a oclusão perfeita, preconizadas por Andrews ${ }^{5,6}$, possam ser uma meta segura e factível, admitese que para se ter uma oclusão perfeita, quer seja natural ou através do tratamento ortodôntico, há a necessidade de um bom relacionamento entre as bases ósseas apicais. Assim sendo, o arco dentário superior deverá compatibilizar-se com o inferior contendo-o de forma que haja uma perfeita intercuspidação e assim promover o máximo de função com o mínimo de esforço, contemplando a longevidade do sistema estomatognático.

Nos estudos de Andrews ${ }^{2,3,4,5,6}$ para o desenvolvimento das seis chaves para a oclusão perfeita, bem como no do aparelho Straight Wire, o autor não determinou qual era a relação entre as bases ósseas, portanto a posição quanto à inclinação dos incisivos superiores e inferiores não foram consistentes conforme relata em seu livro Straight Wire - O Conceito e o Aparelho, capítulo 4 em conclusões. Deste modo, o estudo apresentado se mostra factível e oportuno, pois a amostra utilizada foi obtida de 57 pacientes tratados com aparelhos Straight Wire padrão, sem extrações, que tiveram como meta e finalização do tratamento conforme as seis chaves para a oclusão perfeita, preconizadas por Andrews ${ }^{5,6}$, em estudo com telerradiografias cefalométricas em norma lateral, modelos ortodônticos em gesso e imagens intrabucais.

\section{REVISÃO DE LITERATURA}

Embora ocupamos uma vasta revisão de literatura para elaboração desta pesquisa destacamos nesta publicação as mais importantes e as dividimos em tópicos para facilitar a leitura e compreensão do texto.

1) Classificação oclusionista,

2) Análises cefalométricas,

3) Plano oclusal,

4) Posicionamento quanto às bases ósseas.

\section{Classificação oclusionista}

Em 1899, Angle ${ }^{9}$ estudou casos de modelos em gesso e publicou na revista "Dental Cosmos" um sistema de classificação das mas oclusões. Foi o primeiro pesquisador a ocupar-se de um método científico para a classificação oclusionista. Mesmo sendo considerada, por alguns, obsoleta e limitada, esta classificação ainda persiste como referência acadêmica para a comunicação entre profissionais. 
O trabalho de Angle ${ }^{9}$, fundamentava-se nas relações dentoclusais, considerando que o primeiro molar superior era estável, e em decorrência desta estabilidade, as variações mesiodistais entre os arcos dentários recebiam denominações distintas: as famosas Classe I, II e III.

Andrews ${ }^{5,6}$ propôs à comunidade ortodôntica internacional uma nova classificação oclusionista. Estudou 120 casos de pacientes com oclusões normais naturais, cujas características eram: 1) nunca haviam sido submetidos a tratamentos ortodônticos, 2) os dentes encontravam-se bem alinhados e com aparência agradável, 3) pareciam ter uma excelente intercuspidação e 4) não receberiam nenhum benefício de um tratamento ortodôntico. Pesquisando modelos em gesso destes pacientes observou que seis características estavam consistentemente presente, e as denominou de "As seis chaves para a oclusão perfeita". Seu trabalho ganhou reconhecimento junto à comunidade ortodôntica internacional de tal forma que hoje não se concebe a idéia de praticar Ortodontia sem este conhecimento.

\section{Análises cefalométricas}

Os estudos cefalométricos ganharam notoridade em 1936, quando Tweed ${ }^{24}$, discordando de Angle ${ }^{9}$, causou grande impacto na comunidade ortodôntica internacional ao promover as extrações dentárias, sendo que, até então, era inconcebível tal procedimento. Tais procedimentos eram necessários, pois após 6 anos de utilização da recomendação de Angle ${ }^{9}$, constatou em seus pacientes que, por vezes, mantendo a presença de todos os dentes na boca, freqüentemente protrusões antiestéticas e/ou recidivas ocorriam. Deste modo, passou a indicar extrações dos primeiros pré-molares nos casos de biprotrusão ou protrusão superior, enfatizando a importância do uso da ancoragem, sem a qual as posições finais seriam insatisfatórias.

Desde então, outros pesquisadores ${ }^{13,22,25}$ passaram a ocupar as análises cefalométricas como referências para subsidiar o diagnóstico e plane- jamento.

Tweed $^{25}$, avaliando uma amostra de 95 indivíduos portadores de estética facial satisfatória, observou, independentemente da existência ou não de má oclusão, os valores médios das medidas: FMA era de $24,57^{\circ}$, com limites de variações entre 15 a $36^{\circ}$; IMPA era de $86,96^{\circ}$ com limite de variações entre 76 a $99^{\circ}$; FMIA era de $68,20^{\circ}$, com limite de variações entre 56 a $80^{\circ}$. Tweed ${ }^{25}$ acreditava que estes valores proporcionariam uma estética facial satisfatória e resultados finais mais estáveis; entretanto, enfatizou a importância do padrão facial, admitindo compensações na inclinação dos incisivos inferiores.

Steiner ${ }^{22}$ escolheu um conjunto de desenhos expressando o seu conceito de medidas médias de jovens americanos $\left(\mathrm{ANB}=2^{\circ}, 1 . \mathrm{NA}=22^{\circ}\right.$, $\left.1-\mathrm{NA}=4 \mathrm{~mm}, 1 . \mathrm{NB}=25^{\circ}, 1-\mathrm{NB}=4 \mathrm{~mm}\right)$. Orientou que podiam e deviam ser modificadas, na dependência do conceito de harmonia facial do profissional e quando ocorrem más oclusões. Essas modificações são quanto às medidas e proporção entre elas. Recomendou a necessidade de avaliar outros fatores como idade, gênero, raça, potencial de crescimento e as variações individuais, para se efetuar um planejamento adequado para cada paciente. Com a evolução das pesquisas, o ângulo ANB começou a receber críticas quanto à sua confiabilidade.

Jacobson ${ }^{13}$ demonstrou diversas situações em que o ângulo ANB não permite uma correta avaliação do relacionamento entre as bases apicais, entre estas situações estão: 1) A localização ântero-posterior do ponto $\mathrm{N}$ com as bases apicais, mostrando que o posicionamento mais para anterior ou posterior do násio influencia diretamente na leitura do ângulo ANB. 2) O efeito rotacional dos maxilares, quer no sentido horário ou anti-horário dos maxilares em relação aos planos de referência cranianos (linha SN), modificam totalmente o ângulo ANB. Baseado nestas considerações, Jacobson ${ }^{13}$ propôs a avaliação WITS (Universidade Witwatersrand - Johannesburg, África do Sul) que intencionou 
relacionar a maxila e a mandíbula através de um plano de referência comum aos dois arcos dentários, que é o plano oclusal. Concluiu afirmando que a intenção da avaliação WITS era ser utilizada como um auxílio a outras análises, salientando que a avaliação WITS permite identificar as falhas ocasionadas pela leitura do ângulo ANB, sendo uma mensuração razoavelmente confiável para a determinação da extensão da desarmonia ânteroposterior das bases ósseas apicais.

\section{Plano oclusal}

Inúmeros autores ${ }^{11,14,18,20,23}$ tem pesquisado o comportamento do plano oclusal.

Robertson e Pearson ${ }^{18}$ observaram que, na avaliação Wits, nem sempre é fácil identificar o plano oclusal com precisão.

Sherman et al. ${ }^{20}$ avaliaram o comportamento da avaliação Wits e concluíram que esta deve ser usada como um auxílio para o diagnóstico, pois poderão ocorrer alterações na angulação do plano oclusal, que poderão interferir com a relação ântero-posterior entre a maxila e mandíbula, bem como no crescimento diferencial do pogônio em relação ao ponto $B$, especialmente no gênero masculino.

Jacobson ${ }^{14}$, revisando os principais aspectos da avaliação Wits, desde sua introdução em 1975, afirmou que este método é muito dependente da correta localização ou representação do plano oclusal. Os problemas podem ocorrer porque o plano oclusal não é plano e como os dentes posteriores de ambos os lados nem sempre coincidem, podem apresentar sobreposição devido a uma assimetria dentofacial, e ou posição incorreta da cabeça no cefalostato. Muito embora esses fatores, dentre outros, possam limitar a exatidão e precisão das medidas cefalométricas, pode-se obter excelentes informações nestas radiografias. O plano oclusal, tradicionalmente, estende-se da imagem da sobreposição das cúspides dos primeiros molares permanentes até o ponto médio da sobremordida dos incisivos. Porém, devido à pos- sibilidade de supra ou infraversão dos incisivos, é mais apropriado traçar o plano oclusal passando pelas cúspides dos primeiros molares e primeiros pré-molares. No caso eventual de uma discrepância entre os lados direitos e esquerdos dos dentes posteriores, traça-se o plano no meio entre os dois segmentos.

Canuto $^{11}$ pesquisou a influência de três métodos de traçado do plano oclusal, analisando os resultados que revelaram que a avaliação Wits é bastante influenciada pela inclinação do plano oclusal.

\section{Posicionamento quanto às inclinações dos in- cisivos}

Diversos pesquisadores têm se ocupado dos estudos cefalométricos para determinar qual o posicionamento ideal dos incisivos ao final do tratamento ortodôntico e, conseqüentemente, a interpretação dos desvios e intensidades que estes possam apresentar nas más oclusões.

Tweed ${ }^{27}$ destacou que os incisivos inferiores deveriam apresentar-se posicionados corretamente no processo alveolar, sem invadir a cortical óssea compacta ao final do tratamento, nos casos onde os padrões esqueléticos eram bons. Para tal ocupou um triângulo determinado no traçado cefalométrico, onde destacou a necessidade de compreender a importância das variações angulares, formado pelo plano de Frankfurt (Po-Or) e pelo plano mandibular (Go-Me), ângulo este que denominou de FMA. Quando este ângulo apresentar $16^{\circ}$ a $35^{\circ}$, em média, prognóstico será favorável quanto menor for o valor exibido, opostamente quanto maior maior for este ângulo mais difícil o prognóstico.

Steiner ${ }^{21}$ determinou o posicionamento quanto à inclinação dos incisivos através métodos matemáticos disponibilizados em uma tabela de suporte onde, através de equações matemáticas, se determinavam as inclinações dos incisivos superiores 1.NA e as dos inferiores 1.NB através da estimativa final da medida $A N B$, que representa a relação 
entre as bases ósseas.

Andrews $^{6}$, através de aferições, estudou 120 casos de pacientes com oclusões normais naturais, e desenvolveu as seis chaves para a oclusão perfeita. Adicionalmente, elaborou um aparelho de natureza tridimensional denominado Straight Wire. Para estes estudos tomou como ponto de referência o centro da coroa clínica dos dentes e, através deste, determinou o longo eixo vestibular da coroa clínica (EVCC), porção mais preeminente do lóbulo central da superfície vestibular de todos os dentes, exceto para os molares, onde o eixo vestibular da coroa clínica foi determinado pelos sulcos vestibulares que separam as duas grandes cúspides. Sobre o eixo vestibular determinou um ponto que separa a metade gengival da coroa clínica da metade oclusal e o denominou de ponto do eixo vestibular (ponto EV). Ocupando-se de métodos apropriados, mensurou as superfícies vestibulares dos dentes, tomando como referência o ponto $\mathrm{EV}$, e determinou para cada elemento dentário a área dos braquetes e tubos, contornos horizontais e verticais, para compatibilizá-los de forma precisa e individualizada para cada elemento dentário, respeitando as proeminências vestibulares individuais para cada tipo de dente. Deste modo, considerando que quando estes estivessem com seus encaixes compatibilizados aos arcos retangulares no final do tratamento, os arcos e seus respectivos elementos dentários estariam devidamente alinhadas, niveladas, com suas angulações, inclinações e compensações molares, reproduzindo o posicionamento e os valores encontrados na aferição dos estudos que determinaram as seis chaves para a oclusão perfeita. No estudo das medições, Andrews ${ }^{5}$ revelou consistências de posição (exceto para a inclinação do incisivo), morfologia e proeminência vestibular relativa nas coroas de cada tipo de dente em uma arcada. As diferenças na inclinação dos incisivos eram atribuídas à discrepância entre os maxilares. Portanto, deve ser dada uma consideração especial ao desenho do braquete para correlacionar a inclinação dos incisivos com a relação entre os maxilares. Basicamente os aparelhos Straight Wire possuem braquetes e tubos com características diferenciais, ou seja, aparelhos padrões para tratamentos sem extrações ou pequenos movimentos e aparelhos para movimentos de translações dos dentes, geralmente ocupados para tratamentos que requeiram extrações. Adicionalmente, Andrews ${ }^{5}$ prescreveu três conjuntos de braquetes com variações nas inclinações para uso nos incisivos centrais superiores e inferiores (Classe I: superior $+7^{\circ}$ e inferior $-1^{\circ}$, Classe II: superior $+2^{\circ}$ e inferior +4 e Classe III: superior $+12^{\circ}$ e inferior $-6^{\circ}$ ). A combinação no uso destes conjuntos visa compensar possíveis variações ântero-posteriores entre as bases ósseas. Estes conjuntos de aparelhos e suas combinações permitem cobrir doze tipos de tratamentos. Estes aparelhos foram concebidos de modo que, ao finalizar o tratamento ortodôntico com os arcos retangulares, devam estar embutidos nos encaixes dos braquetes e, deste modo, os arcos dentários e seus respectivos elementos possam estar com suas angulações e inclinações de acordo com suas prescrições.

\section{PROPOSIÇÃO}

1) Verificar se há correlação no comportamento da variação das bases ósseas (Wits) ${ }^{13}$ e as inclinações dos incisivos centrais superiores e inferiores, em casos tratados ortodonticamente, de acordo com as seis chaves para a oclusão perfeita ${ }^{5,6}$;

2) Avaliar os valores das inclinações dos incisivos através do método radiográfico, nas telerradiografias em norma lateral;

3) Comparar os valores obtidos neste estudo, quanto às inclinações dos incisivos centrais superiores e inferiores, com os valores propostos por Andrews ${ }^{5}$.

\section{MATERIAL E MÉTODOS}

A amostra utilizada neste estudo pertence ao arquivo da clínica privada Perfil Ortodôntico da 
cidade de Curitiba, estado do Paraná, Brasil, sendo formada por 57 telerradiografias cefalométricas em norma lateral, modelos ortodônticos em gesso e imagens intrabucais, sendo 31 do gênero feminino com idade média de 15 anos e 5 meses, e 26 do gênero masculino com idade média de 15 anos e 5 meses. Não foram estabelecidos critérios raciais, culturais ou sócio-econômicos; apenas a distribuição entre os dois gêneros e suas respectivas faixas etárias.

Estes pacientes foram tratados com aparelhos Straight Wire padrão, sem extrações, e tiveram como meta a finalização do tratamento segundo as seis chaves para a oclusão perfeita, preconizadas por Andrews ${ }^{5,6}$.

\section{Estudo cefalométrico}

As terradiografias foram utilizadas para determinar o relacionamento entre as bases ósseas, empregando-se a mensuração Wits, preconizada por Jacobson ${ }^{13}$. Bem como de interesse associado, mensurações para se observar e estudar os comportamentos dos incisivos centrais superiores (ICs) e inferiores (ICi) quanto às suas inclinações através de uma adaptação do modo de aferição de modelos utilizado por Andrews ${ }^{5}$, quando desenvolveu o aparelho Straight-Wire. Ambos os métodos foram usados nestes estudos, ou seja, o cefalométrico e o de modelo.

As telerradiografias cefalométricas em norma lateral foram obtidas em dois institutos distintos, onde um utilizou aparelho de raios X marca Unimax - Siemens com $6 \%$ de magnificação e o outro Orthopantomografo Siemens modelo Orthophos Cd com $10 \%$ de magnificação.

As estruturas anatômicas ocupadas para o traçado foram: perfil mole, sutura fronto-nasal, sela túrcica,contorno orbitário, meato acústico externo (oliva metálica), fissura pterigomaxilar, osso maxilar, osso mandibular, incisivos centrais superiores (ICs) e inferiores (ICi), com limite cervical dividindo a coroa da raiz, primeiros molares superiores e inferiores

\section{Pontos}

Os pontos anatômicos utilizados foram: ponto $\mathrm{A}$, ponto $\mathrm{B}$, ponto $\mathrm{EV}$ - ponto sobre o eixo vestibular que separa a metade gengival da coroa clínica da metade oclusal, ocupado tanto para mensurações em telerradiografias como para as de modelos em gesso, quando da obtenção das inclinações dos incisivos centrais superiores (ICs) e inferiores (ICi). Entretanto, para a sua localização primeiramente é necessário determinar o eixo vestibular da coroa clínica (EVCC), que corresponde à porção mais proeminente do lóbulo central da superfície mais vestibular da coroa. Em modelos de gesso, pode-se obtê-lo através da face lateral da grafite de um lápis, tocando por vestibular e deslizando no sentido cérvico-incisal. Desta forma o grafite irá demarcar o lóbulo mais proeminente, que é o eixo vestibular da coroa clínica (EVCC).

Demarcado o eixo vestibular da coroa clínica (EVCC), o ponto EV é encontrado baseado numa perpendicular que toca e divide a metade incisal da cervical.

Já na telerradiografia cefalométrica em norma lateral, pode-se localizar demarcando o limite vestibular externo dos incisivos centrais superiores e inferiores a uma mesma distância entre a incisal e a cervical do traçado, quando avaliado da perspectiva mesial ou distal.

Tanto nos modelos como nas telerradiografias, o ponto EV foi usado por perspectiva mesial e distal como referência anatômica, e usado para avaliar a inclinação, mediante o emprego de uma linha reta que é paralela e tangente a um ponto do EVCC, que separa a metade gengival da incisal (ponto EV).

\section{Linhas}

Linha AO: perpendicular que vai do ponto A ao plano oclusal.

Linha BO: perpendicular que vai do ponto $\mathrm{B}$ ao plano oclusal. 


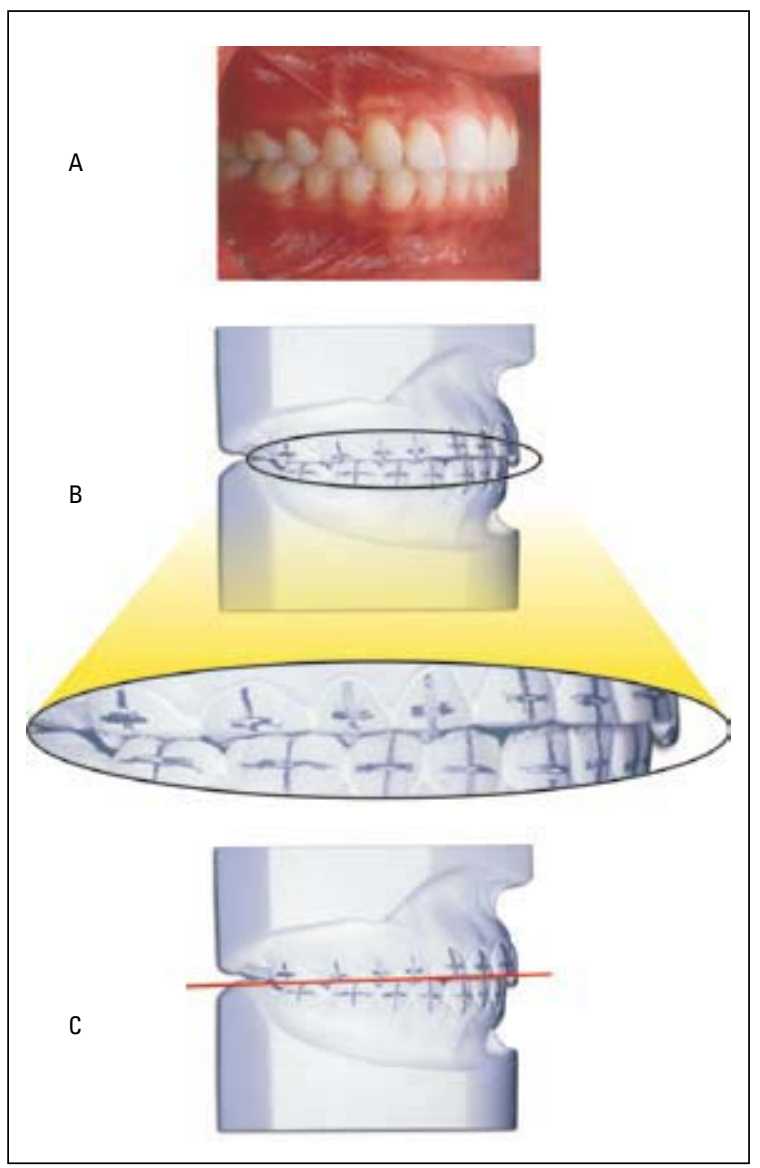

FIGURA 1A, 1B, 1C - As figuras demonstram o método utilizado para se determinar o plano oclusal cefalométrico.

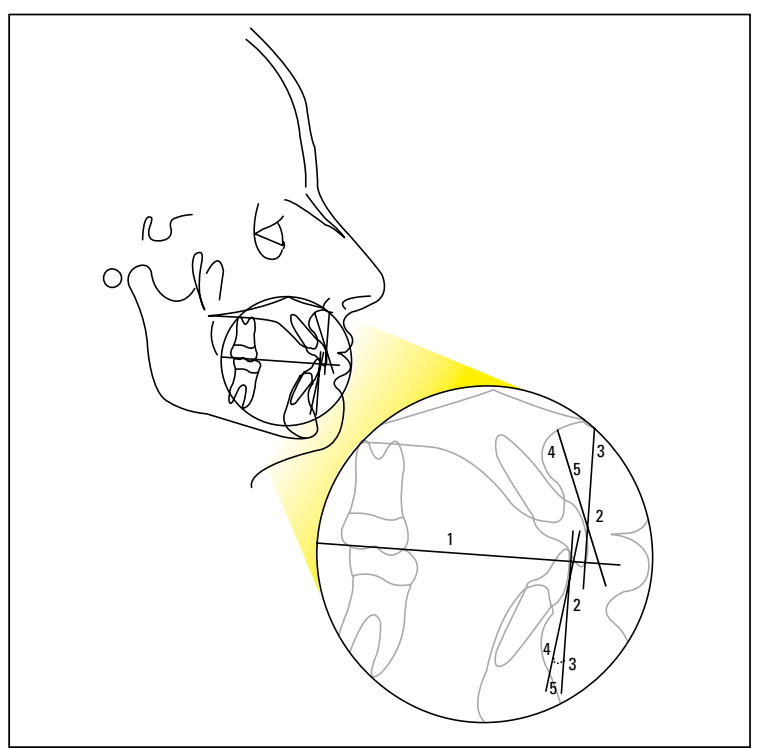

FIGURA 2 - 1) Plano Oclusal Cefalométrico, 2) Pontos EVs, 3) Perpendiculares ao plano oclusal, 4) Tangentes aos pontos EVs, 5) Ângulos que determinam as inclinações dos ICs e ICi.

\section{Plano}

O plano oclusal foi obtido medianteobservações visuais dos modelos de pacientes tratados com aparelhos Straight Wire padrão, utilizados para esta pesquisa. Para tais observações foram cortadas as cúspides vestibulares da hemi arcada superior e as cúspides linguais dos molares e prémolares inferiores no modelo para se ter acesso visual a este plano, quando então revelaram toques uniformes das cúspides dos molares e pré-molares inferiores nos sulcos oclusais dos arcos superiores (Fig. 1A, B, C). Considerando ser este o plano oclusal revelado nos modelos como o ideal, transferimos deste modo para os estudos cefalométricos, onde o plano oclusal foi determinado através de um segmento de reta traçado no sentido pósteroanterior a aproximadamente um centímetro distal dos primeiros molares inferiores, tangenciando suas cúspides, prolongando-se anteriormente, tangenciando as cúspides dos pré-molares inferiores no cefalograma.

\section{Tangentes}

Duas linhas tangentes aos pontos EVs foram utilizadas para se determinar os graus de inclinações dos incisivos centrais superiores (ICs) e inferiores (ICi): uma ascendente ao plano oclusal e paralela ao eixo vestibular da coroa clínica (EVCC), de modo a tangenciar o ponto EV do incisivo central superior (ICs) no traçado; e outra descendente e também paralela ao longo eixo vestibular da coroa clínica (EVCC) tangente ao ponto EV do incisivo central inferior (ICi).

\section{Grandezas lineares e angulares (Mensura- ções)}

\section{Ângulos (Grandezas angulares) (Fig. 2)}

Dois ângulos foram utilizados para se obter o grau de inclinação dos incisivos: para os incisivos centrais superiores (ICs) o ângulo formado pela confluência das duas linhas ascendentes ao plano oclusal, sendo uma perpendicular e outra tangen- 
te ao ponto EV da coroa do incisivo central superior (ICs). Para os inferiores, a confluência de duas linhas iguais, porém descendentes ao plano oclusal.

Os ângulos foram considerados positivos quando a tangente ao ponto EV se posicionava à direita da perpendicular ao plano oclusal e negativos quando se posicionava à esquerda.

\section{Linear (Grandezas lineares) (Fig. 3)}

Para se aferir os valores e quantificar as variações entre as bases ósseas foi utilizada a avaliação Wits $^{13}$ na distância linear no plano oclusal entre $\mathrm{AO}$ e $\mathrm{BO}$.

\section{Estudo de modelos}

Por meio de modelos ortodônticos, gabarito de acrílico oclusal (Fig. 4) e transferidor com braço de leitura ajustável (Fig. 7), foram aferidos valores que pudessem revelar os comportamentos quanto às inclinações dos incisivos centrais superiores direito (D11) e esquerdo (D21),

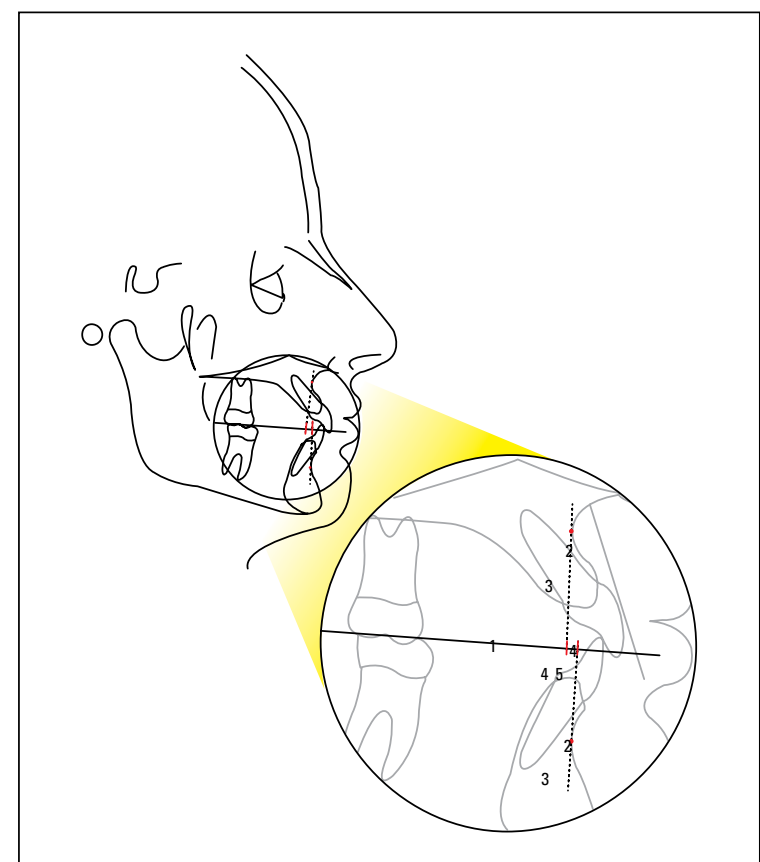

FIGURA 3 - 1) Plano oclusal cefalométrico, 2) Pontos $A$ e $B, 3)$ Perpendiculares ao plano oclusal (linhas A0-B0), 4) Ponto A0 e B0,5) Distância linear para Wits. bem como os inferiores direito (D31) e esquerdo (D41), tomando como referência o método ocupado por Andrews ${ }^{5}$ quando desenvolveu o aparelho Straight Wire.

\section{Metolodogia para obtenção das medidas em modelos}

\section{Passo 1}

Inicialmente, utilizando os modelos ortodônticos, foram demarcados os eixos vestibulares das coroas clínicas (EVCCs) dos incisivos centrais superiores direito (D11), esquerdo (D21), e inferiores direito (D31) e esquerdo (D41) através da face lateral do grafite lápis preto. Em seguida, com

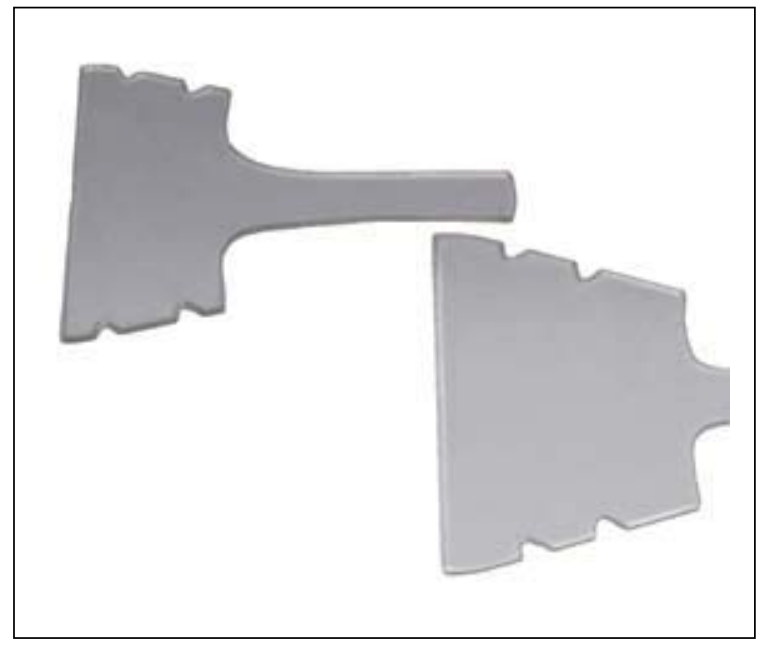

FIGURA 4 - Gabarito de acrílico para apoio oclusal em modelos.

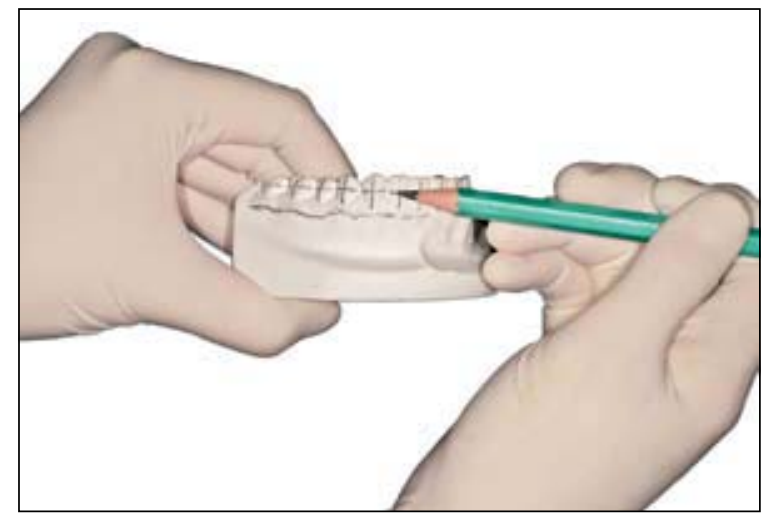

FIGURA 5 - Demarcação do eixo vestibular da coroa clínica (EVCC) e o ponto do eixo vestibular (EV). 
a ponta do lápis foram traçadas perpendiculares dividindo a metade oclusal da metade cervical dos EVCCs. Nos locais onde estas perpendiculares cruzavam o EVCCs encontramos os pontos EVs (Fig. 5).

\section{Passo 2}

Após a marcação dos pontos EVs, cada par de modelos foi apoiado em uma mesa de forma que as superfícies oclusais ficassem voltadas para cima, e apoiamos na superfície oclusal destes modelos o gabarito de acrílico oclusal dos arcos dentários. A base plana do transferidor com braço de leitura ajustável foi apoiada na superfície oclusal do gabarito acrílico, e o braço ajustável foi regulado para tocar o ponto EV de cada elemento dentário (Fig. 6).

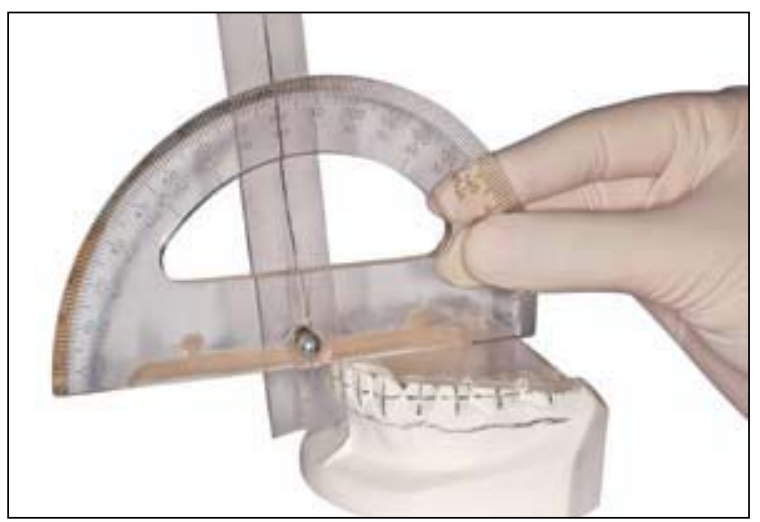

FIGURA 6 - Utilização do gabarito oclusal.

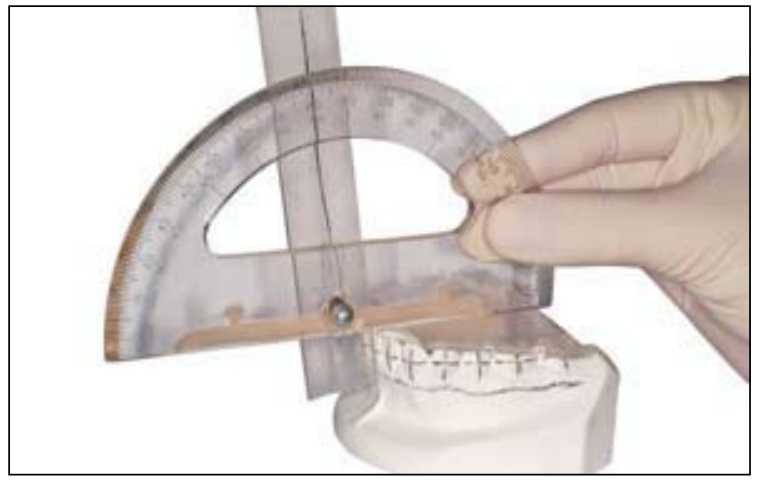

FIGURA 7 - Grau de inclinação do transferidor.

\section{Passo 3}

Com o braço ajustável tocando o ponto EV, a extensão oposta do braço determinou o grau de inclinação, através da leitura por compatibilidade entre braço ajustável e o valor numérico do transferidor (Fig. 7).

\section{Estudo de avaliações fotográficas}

Por ter sido o livro Straight Wire - o conceito e aparelho ${ }^{5}$ objeto de freqüente consulta neste trabalho, vimos que este oferece a possibilidade de avaliar de maneira lógica e criteriosa, as metas de um excelente tratamento ortodôntico através das seis chaves para a oclusão perfeita. Por ter sido os 57 casos da amostra tratada com este objetivo, procuramos aferir o grau de qualidade da amostra apresentada.

\section{Metodologia para o julgamento das seis cha- ves para a oclusão perfeita}

As avaliações fotográficas permitem avaliar a quantidade de desvios, suas intensidades e conseqüentemente a qualidade dos resultados obtidos, entretanto destacamos, como descreve Andrews ${ }^{5}$, que o grau exato de angulação ou inclinação não pode ser precisado, mas a natureza, se é positiva ou negativa ou excedente, pode.

Para a avaliação dos casos tratados, as oclusões foram observadas em imagens intrabucais de vistas frontal, lateral direita e esquerda, oclusais superiores e inferiores.

As chaves avaliadas foram:

Chave I: relação interarcos do segmento posterior em milímetros.

Chave II: dentes incorretamente angulados.

Chave III: dentes incorretamente inclinados.

Chave IV: dentes rotacionados.

Chave V: localização de espaços não relacionados com a discrepância no tamanho de um dente.

Chave VI: profundidade da curva de Spee, quando for maior que $2,5 \mathrm{~mm}$.

Na tabela de referência (Tab. 1), observamos os critérios para avaliações das imagens e o grau de 
Tabela 1 - Critérios para avaliação dos modelos.

\begin{tabular}{|c|c|c|c|c|c|}
\hline \multicolumn{6}{|c|}{ Grau de variação das condições perfeitas } \\
\hline & A & B & C & D & $\mathbf{E}$ \\
\hline Chave I & $-\ldots$ & $0,5-1,5 \mathrm{~mm}$ & $1,6-2,0 \mathrm{~mm}$ & $2,1-2,5 \mathrm{~mm}$ & $2,6 \mathrm{~mm}$ ou mais \\
\hline Chave II & $-\ldots$ & 1-2 dentes incorretos & 3-4 dentes incorretos & 5-6 dentes incorretos & 7 ou mais dentes incorretos \\
\hline Chave III & $-\ldots$ & 1-2 dentes incorretos & 3-4 dentes incorretos & 5-6 dentes incorretos & 7 ou mais dentes incorretos \\
\hline Chave IV & $-\ldots$ & 1-2 dentes rotacionados & 3-4 dentes rotacionados & 5-4 dentes rotacionados & 7 ou mais dentes rotacionados \\
\hline Chave V & $-\ldots$ & 1 espaço & 2 espaços & 3 espaços & 4 ou mais espaços \\
\hline Chave VI & $\ldots$ & $3 \mathrm{~mm}$ & $4 \mathrm{~mm}$ & $5 \mathrm{~mm}$ & $6 \mathrm{~mm}$ ou mais \\
\hline
\end{tabular}

variações das condições perfeitas.

As avaliações foram registradas em um formulário onde constavam espaços para anotações dos seguintes dados: caso, gênero, idade. Abaixo estão seis algarismos romanos identificando as chaves; logo à direita de cada algarismo romano existe espaço para anotar as condições incorretas ou uma barra de Palmer para anotar os dentes incorretos. No extremo de cada numeral está um espaço, para anotar o grau de cada chave. Exemplo:

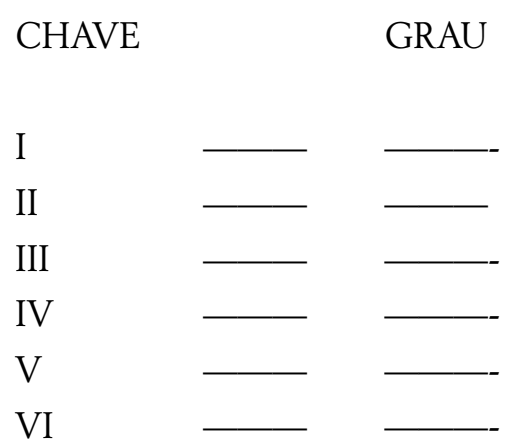

Os 57 casos foram avaliados, e os graus de irregularidades de cada chave convertidos numa letra equivalente a valores numéricos:

$$
\begin{aligned}
& A=4 \\
& B=3 \\
& C=2 \\
& D=1 \\
& E=0
\end{aligned}
$$

Em seguida foram obtidas as médias destes valores e convertidas novamente para uma letra equivalente (Tab. 2). Exemplo de um caso da amostra e a sua qualificação (Fig. 8-14).
Tabela 2

\begin{tabular}{cc}
\hline \multicolumn{2}{c}{ Equivalentes de Graduação } \\
A & $4.0-3.7$ \\
A- & $3.6-3.5$ \\
B+ & $3.4-3.3$ \\
B & $3.2-2.7$ \\
B- & $2.6-2.5$ \\
C+ & $2.4-2.3$ \\
C & $2.2-1.7$ \\
C- & $1.6-1.5$ \\
D+ & $1.4-1.3$ \\
D & $1.2-0.7$ \\
D- & $0.6-0.5$ \\
E+ & $0.4-0.3$ \\
E & $0.2-0.0$ \\
\hline
\end{tabular}

\section{Estudo estatístico}

Para verificar o erro sistemático intra e interexaminador foi utilizado o teste $t$ pareado. $\mathrm{Na}$ determinação do erro casual utilizou-se o cálculo de erro proposto por Dahlberg ${ }^{28}$.

Os resultados das avaliações do erro sistemático, avaliado pelo teste $t$ pareado, e do erro casual medido pela fórmula de Dahlberg ${ }^{28}$ estão mostrados na tabela 3 .

$\mathrm{O}$ erro casual intra e interexaminadores variaram na faixa de $0,22^{\circ}$ a $0,32^{\circ}$ para as medidas executadas nos modelos, enquanto nas medidas o erro casual intra e interexaminadores variou na faixa de $0,22^{\circ}$ a $0,32^{\circ}$ para as medidas executadas 

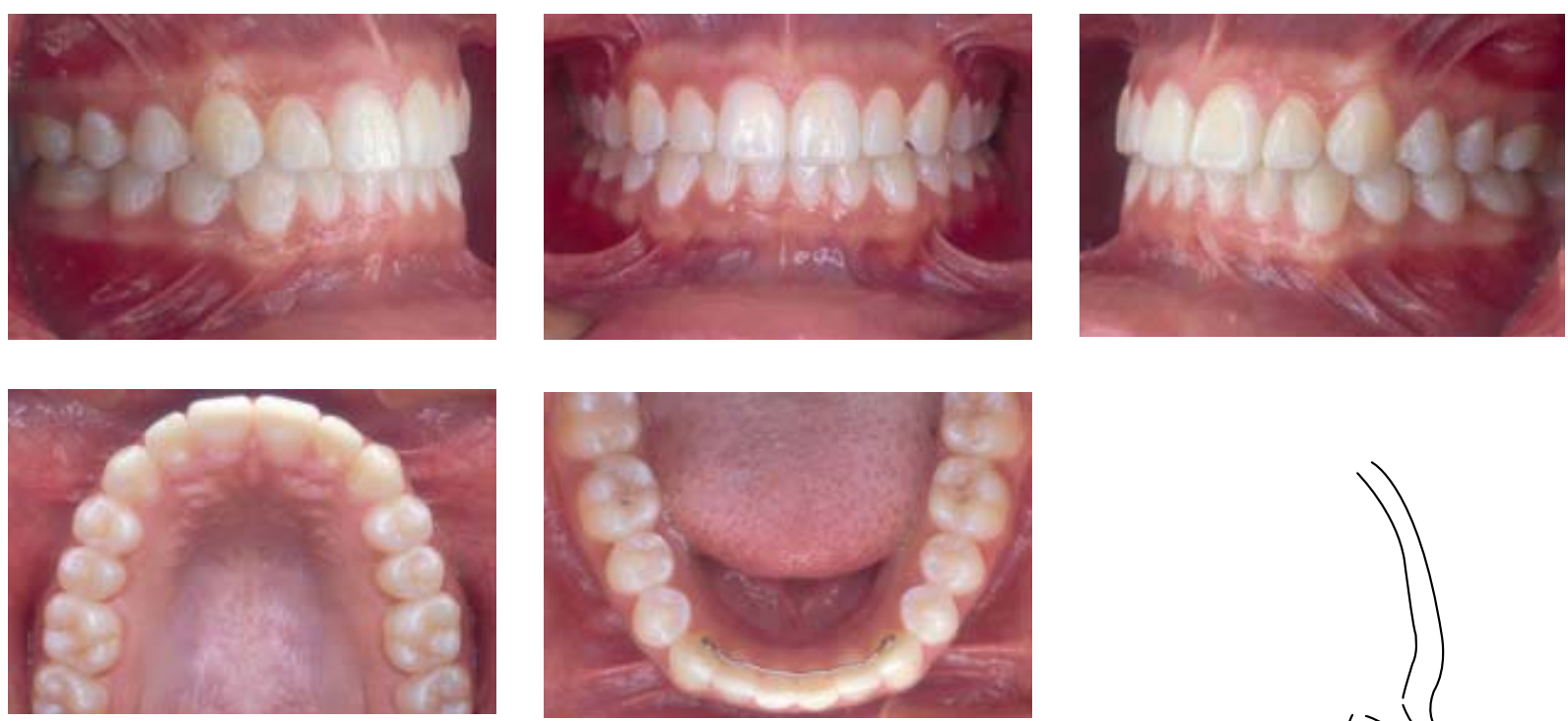

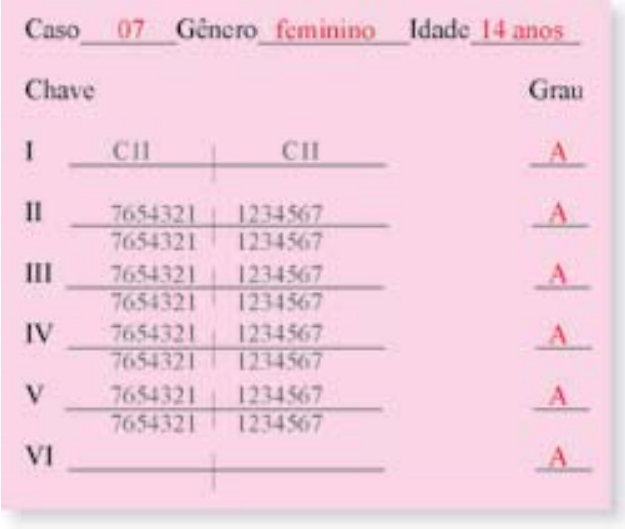

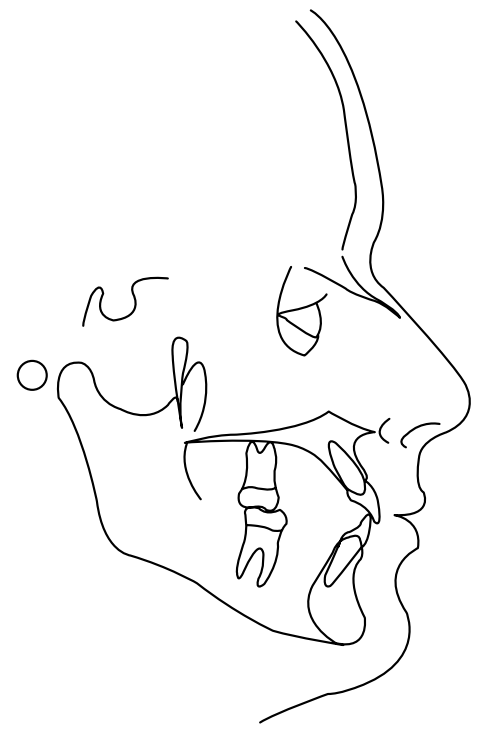

FIGURAS 8-14 - Imagens intrabucais do paciente do gênero feminino da amostra deste trabalho e respectivo traçado cefalométrico final e sua qualificação segundo Andrews ${ }^{4}$. nos modelos, enquanto nas medidas radiográficas o erro casual ficou entre $0,99^{\circ}$ e $1,34^{\circ}$. Isto mostra que as medidas radiográficas possuíram uma menor reprodutibilidade, tanto intra como interexaminadores, do que as medidas nos modelos.

O erro sistemático não foi estatisticamente significante exceto nas medidas D11/21 e Wits interexaminadores, e na medida D31/41 intra-examinadores. Na medida D11/21 interexaminadores a diferença das duas médias foi de $0,12^{\circ}$, na medida Wits interexaminadores a diferença das duas médias foi de $0,14 \mathrm{~mm}$, e na medida D31/41 intraexaminador foi de $0,10^{\circ}$. Do ponto de vista clínico estas diferenças não são relevantes (Tab. 3).
Os dados foram analisados por meio de tabelas e gráficos contendo valores de média e desvio padrão.

Para comparar as diferenças entre os grupos masculino e feminino foi utilizado o teste $t$ de Student. Para a comparação entre as médias das medidas ICs com D11/21, ICi com D31/41 foi utilizado o teste $t$ pareado.

Para verificar as correlações entre as medidas ICs com D11/21, e ICi com D31/41 e a correlação da avaliação Wits com os posicionamentos das inclinações dos incisivos mensuráveis em telerradiografia e modelos em gesso foi utilizado o Coeficiente de Correlação de Pearson. 
Estudo da correlação do posicionamento dos incisivos superiores e inferiores com a relação ântero-posterior das bases ósseas

Tabela 3 - Média, desvio padrão das duas medições, teste $t$ pareado, e erro de Dahlberg para avaliar o erro sistemático e casual.

\begin{tabular}{|c|c|c|c|c|c|c|c|c|}
\hline \multirow[b]{2}{*}{ Medida } & \multirow[b]{2}{*}{ Condição } & \multicolumn{2}{|c|}{ Medição 1} & \multicolumn{2}{|c|}{ Medição 2} & \multirow[b]{2}{*}{$t$} & \multirow[b]{2}{*}{$\mathbf{p}$} & \multirow[b]{2}{*}{ erro } \\
\hline & & Média & $d p$ & Média & $d p$ & & & \\
\hline \multirow{2}{*}{ ICs } & Intra-exam. & 13,55 & 4,35 & 13,25 & 4,66 & 1,681 & $0,098 \mathrm{~ns}$ & 0,99 \\
\hline & Interexam. & 13,55 & 4,35 & 13,54 & 4,63 & 0,035 & $0,972 \mathrm{~ns}$ & 1,34 \\
\hline \multirow{2}{*}{ ICi } & Intra-exam. & 5,14 & 7,05 & 5,43 & 6,68 & 1,285 & $0,204 \mathrm{~ns}$ & 1,21 \\
\hline & Interexam. & 5,14 & 7,05 & 5,17 & 6,56 & 0,105 & $0,917 \mathrm{~ns}$ & 1,32 \\
\hline \multirow{2}{*}{ D11/21 } & Intra-exam. & 7,96 & 3,28 & 7,88 & 3,14 & 1,514 & $0,136 \mathrm{~ns}$ & 0,30 \\
\hline & Interexam. & 7,96 & 3,38 & 7,86 & 3,13 & 2,016 & $0,48^{*} \mathrm{~ns}$ & 0,27 \\
\hline \multirow{2}{*}{ D31/41 } & Intra-exam. & 5,03 & 4,81 & 4,93 & 4,74 & 2,414 & $0,019^{*}$ & 0,22 \\
\hline & Interexam. & 5,03 & 4,81 & 4,92 & 4,57 & 1,952 & $0,056 \mathrm{~ns}$ & 0,32 \\
\hline \multirow{2}{*}{ WITS } & Intra-exam. & $-2,26$ & 1,83 & $-2,25$ & 1,84 & 0,814 & $0,419 \mathrm{~ns}$ & 0,11 \\
\hline & Interexam. & $-2,26$ & 1,83 & $-2,12$ & 1,84 & 3,134 & $0,002 *$ & 0,27 \\
\hline
\end{tabular}

$\mathrm{ns}=$ diferença estatisticamente não significante, ${ }^{*}=$ diferença estatisticamente significante $(\mathrm{p}<0,05)$.

Em todos os testes estatísticos adotou-se nível de significância de $5 \%{ }^{28}$. Os testes foram executados no programa Statistica for Windows v. 5.1.

\section{RESULTADOS}

As comparações das médias das medidas analisadas entre os gêneros masculino e feminino estão na tabela 4.

A tabela 5 mostra os valores de média, desviospadrão, mínimo e máximo para todos os indivíduos estudados.

A comparação da média da medida ICs com D11/21 está na tabela 6 . A comparação da média

Tabela 4 - Média, desvio-padrão e teste $t$ para comparação das medidas analisadas entre os gêneros masculino $(n=26)$ e feminino ( $n=31$ ).

\begin{tabular}{ccccccc}
\hline \multirow{2}{*}{ Medida } & \multicolumn{2}{c}{ Masculino } & \multicolumn{2}{c}{ Feminino } & \multirow{2}{*}{ t } & p \\
\cline { 2 - 5 } & Média & dp & Média & dp & & \\
\hline ICs & 13,79 & 4,21 & 13,35 & 4,52 & 0,372 & $0,711^{\text {ns }}$ \\
ICi & 7,02 & 6,02 & 3,56 & 7,55 & 1,884 & $0,065^{n s}$ \\
D11/21 & 7,57 & 2,91 & 8,29 & 3,37 & 0,827 & $0,412^{\text {ns }}$ \\
D31/41 & 6,15 & 4,92 & 4,09 & 4,58 & 1,640 & $0,107^{\text {ns }}$ \\
WITS & $-2,26$ & 1,96 & $-2,27$ & 1,75 & 0,014 & $0,989^{\text {ns }}$ \\
\hline
\end{tabular}

ns $=$ diferença estatisticamente não significante. da medida ICi com D31/41 está na tabela 7.

Os valores das inclinações do ICs, D11/21 podem ser visualizadas no gráfico 1 .

Os valores das inclinações do ICi e D31/41 podem ser visualizadas no gráfico 2 .

A tabela 8 mostra os valores do Coeficiente de Correlação de Pearson entre as medidas ICs e D11/21, e entre ICi e D31/41. Estas correlações podem ser visualizadas nos gráficos 3 e 4 .

As tabelas 9 e 10 mostram respectivamente os valores do Coeficiente de Correlação de Pearson entre as medidas WITS com D11/21e D31/41 e WITS com ICs e ICi.

Tabela 5 - Média, desvio-padrão, valor mínino e valor máximo das medidas analisadas para todos os indivíduos $(n=57)$.

\begin{tabular}{ccccc}
\hline \multirow{2}{*}{ Medida } & \multicolumn{4}{c}{ Inclinação (graus) } \\
\cline { 2 - 5 } & Média & dp & Mínimo & Máximo \\
\hline ICs & 13,35 & 4,35 & 3,50 & 24,00 \\
ICi & 5,14 & 7,05 & $-5,00$ & 30,00 \\
D11/21 & 7,96 & 3,28 & 0,00 & 15,00 \\
D31/41 & 5,03 & 4,81 & $-8,00$ & 15,00 \\
WITS & $-2,26$ & 1,83 & $-6,58$ & 1,41 \\
\hline
\end{tabular}




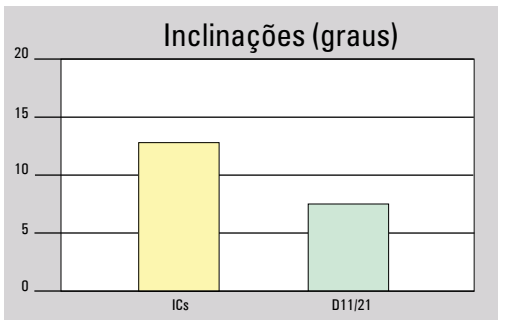

GRÁFICO 1 - Média e desvio padrão das inclinações do ICs, D11/21.

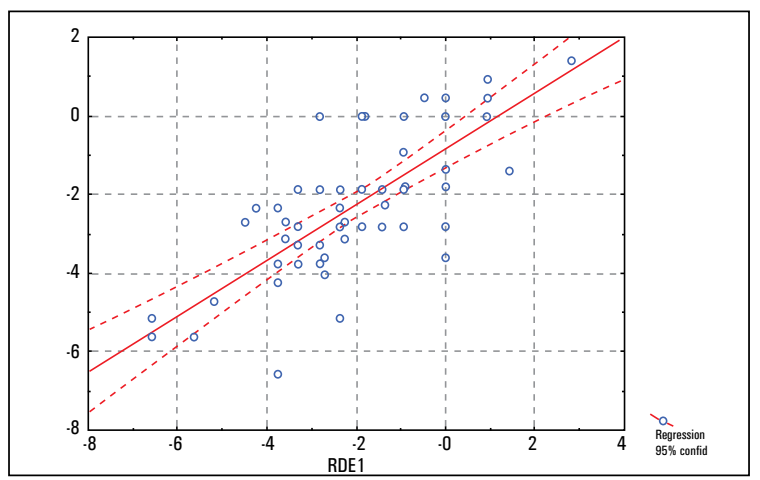

GRÁFICO 3 - Correlação entre ICs e D11/21.

Tabela 6 - Média, desvio-padrão das duas medidas ICs e D11/21 e comparação pelo teste $t$ pareado.

\begin{tabular}{cccccc}
\hline \multicolumn{5}{c}{ ICs } & \multicolumn{4}{c}{ D11/21 } & t & p \\
\cline { 1 - 5 } Média & dp & Média & dp & & \\
\hline 13,35 & 4,35 & 7,96 & 3,28 & 12,298 & $<0,001^{*}$ \\
\hline * - diferença estatisticamente significante $(p<0,05)$. &
\end{tabular}

Tabela 8 - Coeficiente de Correlação de Pearson entre as medidas ICS e D11/21, e entre ICi e D31/41.

\begin{tabular}{ccc}
\hline Correlação & $\mathbf{r}$ & $\mathbf{p}$ \\
\hline $\mathrm{IC}$ × $\mathrm{D} 11 / 21$ & 0,63 & $<0,001^{*}$ \\
$\mathrm{IC}$ $\mathrm{x} \mathrm{D} 31 / 41$ & 0,72 & $<0,001^{*}$ \\
\hline
\end{tabular}

* - correlação estatisticamente significante $(p<0,05)$

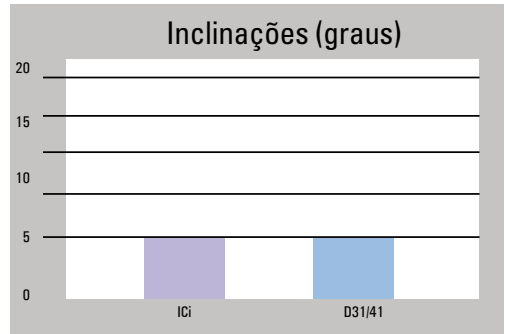

GRÁFICO 2 - Média e desvio padrão das inclinações do ICi, D31/41.

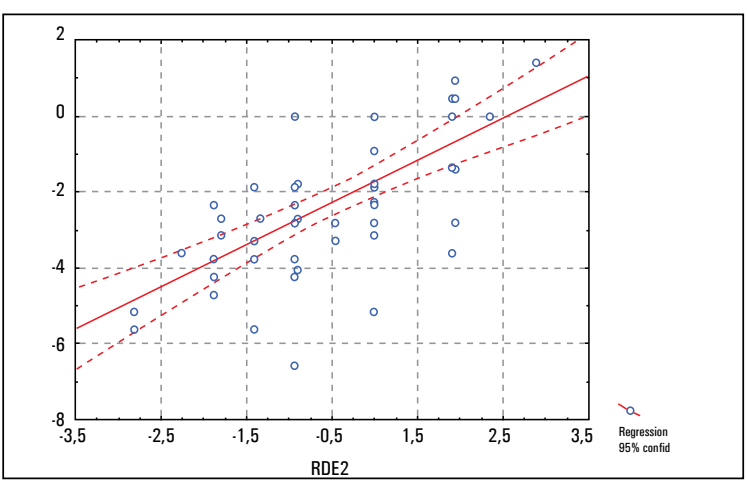

GRÁFICO 4 - Correlação entre ICi e D31/41.

Tabela 7 - Média, desvio-padrão das duas medidas ICi e D31/41 e comparação pelo teste $t$ pareado.

\begin{tabular}{cccccc}
\hline \multicolumn{5}{c}{ ICi } & \multicolumn{4}{c}{ D31/41 } & t & p \\
\cline { 1 - 4 } Média & dp & Média & dp & & \\
\hline 5,14 & 7,05 & 5,03 & 4,81 & 0,169 & $0,867 n s$ \\
\hline * - diferença estatisticamente significante $(p<0,05)$ &
\end{tabular}

Tabela 9 - Coeficiente de Correlação de Pearson entre as medidas WITS com ICs e ICi.

\begin{tabular}{ccc}
\hline Correlação & $\mathbf{r}$ & $\mathbf{p}$ \\
\hline WITS x ICs & $-0,45$ & $<0,001^{*}$ \\
WITS x ICi & 0,45 & $<0,001^{*}$ \\
\hline * - correlacão estatisticamente significante $(p<0,05)$ &
\end{tabular}

Tabela 10 - Coeficiente de Correlação de Pearson entre as medidas WITS com D11/21 e D31/41.

\begin{tabular}{ccc}
\hline Correlação & $\mathbf{r}$ & $\mathbf{p}$ \\
\hline WITS $\times$ D11/21 & $-0,26$ & $0,049^{*}$ \\
& & \\
WITS $\times$ D31/41 & 0,51 & $<0,001^{*}$ \\
\hline * - correlação estatisticamente significante $(p<0,05)$ &
\end{tabular}




\section{DISCUSSÃO}

\section{Concepção do trabalho}

Embora o uso da cefalometria tenha sido recomendado e usado freqüentemente como método auxiliar para o diagnóstico e planejamento ortodôntico, a tentativa de se compatibilizar os valores aferidos das telerradiografias, com os valores preconizados pelas prescrições dos aparelhos ortodônticos Straight Wire ou mesmo os pré-ajustados tem sido incoerente.

Indiferentemente do emprego dos aparelhos Straight Wire, existem problemas associados às prescrições dos aparelhos pré-ajustados, mesmo quando a relação intermaxilares pré-tratamento é conhecida, pois a maioria das análises cefalométricas utilizam a inclinação dos eixos longitudinais dos incisivos centrais para o diagnóstico, enquanto para o tratamento a prescrição dos braquetes totalmente programados (Straight Wire) ou préajustados $1,10,12,16,19,27$ baseia-se na inclinação dos eixos vestibulares da coroa ou a face vestibular das coroas respectivamente.

Assim sendo, admitamos que dispensar o uso das telerradiografias e ocupar só modelos em gesso e a subjetividade clínica para o diagnóstico e planejamento estaremos diante de uma linha tênue próxima do empirismo. Uma outra questão torna-se relevante! Como ensinar academicamente de forma coerente a íntima correlação que há entre a relação das bases ósseas e as inclinações dos incisivos superiores e inferiores, para que os acadêmicos possam tomar decisões seguras e não promover iatrogenias estéticas e ou funcionais em seus futuros pacientes; simplesmente valendo-se da "experiência" ... ciência ou bom senso ... de seus professores?

Esta pesquisa traz a possibilidade de oferecer um método cefalométrico auxiliar que possa ser aplicado de forma coerente e segura tanto pelos acadêmicos como por aqueles que possuem grande experiência profissional e, sobretudo, oferece a possibilidade de pesquisar pré e pós-tratamento a correlação entre bases ósseas de inclinação dos incisivos.

\section{Plano oclusal}

O plano oclusal foi a referência mais importante neste trabalho, pois através dele: 1) Andrews aferiu as inclinações dos incisivos superiores e inferiores para se determinar as prescrições nos aparelhos Straight Wire, 2) método igualmente usado para aferir os valores da amostra neste trabalho, 3) Foi ocupada na avaliação Wits para se determinas a relação entre as bases ósseas, 4) através de perpendiculares a ele tocando o ponto EV e tangentes ao ponto $\mathrm{EV}$ foi possível aferir os valores das inclinações dos incisivos em telerradiografias em norma laterais.

\section{Inclinações dos incisivos centrais superiores e inferiores}

As inclinações dos incisivos revelaram valores diferentes de acordo com o material e método estudado.

Os valores obtidos através de modelos em gesso foram de $+7,96^{\circ}$ para os incisivos superiores (D1 $1 / 21$ ) e de $+5,03^{\circ}$ para os incisivos os inferiores (D31/41), quando comparado com os valores encontrados por Andrews ${ }^{5}$ (superiores $+7^{\circ}$ e inferiores $-1^{\circ}$ ), esta pesquisa revelou uma maior inclinação de $+0,96^{\circ}$ para os superiores e de $+6,03^{\circ}$ para os inferiores.

Os obtidos através de teleradiografias foram de $+13,35^{\circ}$ para os incisivos superiores (ICs) e de $+5,14^{\circ}$ para os incisivos inferiores (ICi) A diferença entre ambos os métodos foi de $+5,39^{\circ}$ para os superiores e de $+0,11^{\circ}$ para os inferiores, lembrando não ser possivel comparar com Andrews ${ }^{5}$, pois ele não ocupou este material e método.

\section{Avaliação Wits}

Os valores da avaliação Wits aferidos nesta pesquisa revelam uma referência normativa de $-2,26 \mathrm{~mm}$ com desvio padrão de $1,83 \mathrm{~mm}$, sem dimorfismo sexual, diferentemente dos encontra- 
dos por Jacobson ${ }^{13}$ onde para gênero masculino a média encontrada foi de $1,17 \mathrm{~mm}$, com desvio padrão de $1,9 \mathrm{~mm}$ (variação de -2 a $4 \mathrm{~mm}$ ), e para gênero feminino, média de $-0,10 \mathrm{~mm}$ com desvio padrão de $1,77 \mathrm{~mm}$ (variação de $-4,5$ a $1,5 \mathrm{~mm})$.

Seguramente dois fatores contribuíram para estas diferenças: a amostra ocupada neste trabalho foi qualificada de acordo com os critérios das seis chaves para a oclusão perfeita de Andrews ${ }^{5,6}$, recebendo nota média de 3,82 de uma escala que variou de mínimo 0 e máximo 4 , adicionalmente o plano oclusal aqui ocupado foi obtido tomando como referência a amostra estudada.

\section{Correlação entre Wits e as inclinações dos incisivos}

Adicionalmente, como houve uma correlação estatisticamente significante entre a avaliação Wits com a inclinação dos incisivos superiores e inferiores obtidos através de cefalometria e modelos em gesso, os resultados permitem afirmar que: tomando como padrão médio Wits $=-2,26$, a medida que as bases ósseas se distanciam positivamente (maxila à frente da mandíbula) os incisivos superiores variam suas inclinações para lingual e os inferiores variam suas inclinações para a vestibular; de modo inverso quando as bases ósseas se distanciam negativamente (maxila atrás da mandíbula) os incisivos superiores variam suas inclinações para vestibular e os inferiores variam suas inclinações para a lingual.

Os valores de referência para estudos cefalométricos são de $+13,35^{\circ}$ quanto às inclinações dos incisivos superiores e $+5,14^{\circ}$ para os inferiores. Adicionalmente destacamos que os incisivos superiores, quando comparados com os valores obtidos por Andrews ${ }^{5}$ revelaram uma inclinação de $+0,96^{\circ}$, enquanto os inferiores de $+6,03^{\circ}$. Se adotados os valores aqui propostos, os tratamentos poderiam ser menos extracionistas, pois permitiriam uma maior vestíbulo-versão dos incisivos inferiores.

\section{Aplicação prática}

Esta pesquisa revela a possibilidade de usar a metodologia cefalométrica aqui desenvolvida (Fig. 2,3) como parâmetro de referência, quando se tem como meta terapêutica as seis chaves para a oclusão perfeita. Para isto, a avaliação Wits deverá ser referenciada com valor normativo de $-2,26 \mathrm{~mm}$ e desvio padrão de $1,83 \mathrm{~mm}$, sem dimorfismo sexual. Já as inclinações dos incisivos, perpendiculares ao plano oclusal tangente ao ponto $\mathrm{EV}$, determinarão as angulações quando mensurados os ângulos

\section{CONCLUSÕES}

De acordo com os materiais e métodos empregados e com os resultados obtidos foi possivel constatar que:

1) Houve correlação quanto ao comportamento da variação das bases ósseas (Wits) ${ }^{13}$ e as inclinações dos incisivos centrais superiores e inferiores, demonstrando que: quando as bases ósseas se distanciam positivamente (maxila à frente da mandíbula) os incisivos superiores variam suas inclinações para lingual e os inferiores variam suas inclinações para a vestibular; de modo inverso quando as bases ósseas se distanciam negativamente o comportamento quanto às inclinações dos incisivos é inverso.

2) Para as aferições cefalométricas os valores das inclinações dos incisivos superiores apresentaram média de $13,35^{\circ}$, enquanto os inferiores uma inclinação média de $+5,14^{\circ}$.

3) Nas aferições em modelos, os valores padrões médios encontrados para as inclinações dos incisivos centrais superiores foi de $+7,96^{\circ}$, enquanto para os inferiores foram de $+5,03^{\circ}$. 


\title{
Maxillary and mandibular incisor position and the skeletal sagital relationship: a correlation study
}

\begin{abstract}
Aim: it was studied the behavior of the dentoskeletal relationship through the Wits appraisal and the acceptable variations of the maxillary and mandibular incisor buccolingual inclinations through different methods using teleradiographies and plaster models. Methods: the sample was comprised by teleradiographs in lateral norm and plasters models from fifty seven brazilian youths, divided in 26 male and 31 females. The age ranged from 15 years and 5 month old for the females and 16 years and 6 month old for the males, orthodontically treated by the Straight-Wire appliance, where a perfect occlusion was prioritized. Results: the normative value for Wits appraisal from this sample was $-2.26 \mathrm{~mm}(\mathrm{SD}=1,83)$, showing no sexual dimorfism. Mean upper incisor inclination was $+13,35^{\circ}$ and mean lower incisor inclination was $+5.14^{\circ}$, when cephalometric measurements were evaluated. From plaster models measurements, the mean inclination pattern for maxillary and mandibular incisor were $+7.96^{\circ}$ and $+5,03^{\circ}$, respectivaly. Conclusion: it was found a significant correlation between skeletal sagital relationship and upper and lower inclinations.
\end{abstract}

Key words: Cephalometric. Normal occlusion. Wits appraisal. Incisor.

\section{REFERÊNCIAS}

1. ALEXANDER, W. The Alexander discipline. Glendora: Ormco Corporation, 1986. p.131

2. ANDREWS, L. F. The straight-wire appliance: explained and compared. J Clin Orthod, Boulder, v. 10, no 3, p. 174-195, Mar. 1976

3. ANDREWS, L. F. The straight-wire appliance: extraction brackets and classification of treatment. J Clin Orthod, Boulder, v. 10, no. 5, p. 360 - 379, May 1976.

4. ANDREWS, L. F. The straight-wire appliance: origin, controversy, commentary. J Clin Orthod, Boulder, v. 10, no. 2, p. 99-114, Feb. 1976

5. ANDREWS. L. F. Straight wire: o conceito e o aparelho. 2. ed. Curitiba: Produções Interativas, 1997.

6. ANDREWS. L. F. The six keys to normal occlusion. Am J Orthod St. Louis, v. 62, no. 3, p. 296-309, Sept. 1972.

7. ANDREWS. L. F. The six elements of orofacial harmony Andrews J, [S. I.], v. 1, no. 1, p. 33-39, Winter 2000

8. ANDREWS. L. F. The six elements of orofacial harmony. Andrews J, [S. I.], v. 1, no. 2, p. 29, Spring 2001

9. ANGLE, E. H. Classification of malocclusion. Dental Cosmos Philadelphia, v. 41, p. 248-264, 1899.

10. BENNETT, J. C. et al. O tratamento ortodôntico da dentição com o aparelho pré- ajustado. São Paulo: Artes Médicas, 1998. p. $47-48$.

11. CANUTO, C. E. Estudo comparativo entre a análise "Wits" (University of the Witwatersrand) e ângulo ANB, na avaliação cefalométrica das relações ântero-posteriores das bases apicais, em casos de oclusão normal. 1981. Dissertação (Mestrado)-Faculdade de Odontologia, Universidade de São Paulo, São Paulo, 1981

12. CAPELOZZA FILHO, L. et al. Individualização de Braquetes na técnica de straight-wire: revisão de conceitos e sugestão de indicações para uso. R Dental Press Ortodon Ortop Maxilar, Maringá, v. 4, n. 4, p. 87-106, jul./ago. 1999.

13. JACOBSON, A. The "Wits" appraisal of jaw disharmony. Am J Orthod, St. Louis, v. 67, no. 2, p.125-138, Feb. 1975.

14. JACOBSON, A. Update on the Wits appraisal. Angle Orthod Appleton, v. 58, no. 3, p. 205-219, July 1988.

15. JACOBSON, A. The craniofacial skeletal pattern of the south Af rican Negro. Am J Orthod, St. Louis, v. 73, p. 544-556, June 1978.
16. McLAUGHLIN, R.; BENNETT J. C.; TREVISI, H. O sistema do aparelho versátil MBT TM o desenvolvimento de uma mecânica e filosofia de tratamento - Parte I. R Dental Press Ortodon Ortop Maxilar, Maringá, v. 3, n. 3, p. 15-23, maio/jun. 1998.

17. ORBAN, B. Oral histology and embryologym. 4th ed. St Louis: C. V. Mosby, 1957

18. ROBERTSON, N. R. E.; PEARSON, C. J. The "Wits" appraisal of a sample of the south wales population. Br J Orhod, Oxford, v. 7, p.183-184, Oct. 1980.

19. ROTH R. H. Five-year clinical evaluation of the Andrews straight wire appliance. J Clin Orthod, Boulder, v.10, p. 836, 1976.

20. SHERMAN, S. L.; WOODS, M.; NANDA, R. S. The longitudina effects of growth on the Wits appraisal. Am J Orthod, St. Louis, v. 93, no. 5, p. 429-436, May 1988.

21. STEINER, C. C. Cephalometric for you and me. Am J Orthod, St. Louis, v. 39, no. 10, p. 729- 755, Oct. 1953.

22. STEINER, C. C. Cephalometric in clinical practice. Angle Orthod, Appleton, v. 29, no. 1, p. 8-29, Jan. 1959

23. THAYER, T. A. Effects of functional versus bisected occlusal planes on the Wits appraisal. Am J Orthod, St. Louis, v. 97, no. 5, p. 422- 426, May 1990.

24. TWEED, C. H. The application of the principle of the Edgewise arch in the treatment of Class II, division I, malocclusions. Part II: a discussion of extraction in the treatment of markeddouble protrusion cases. Angle Orthod, Appleton, v. 4, no. 4 p. 255-257, Oct. 1936

25. TWEED, C. H. The Frankfort mandibular incisor angle (FMIA) in orthodontic diagnosis, treatment planning and prognosis. Angle Orthod, Appleton, v. 24, no. 3, p.121-169, July 1954.

26. TWEED, C. H. The Frankfort: mandibular plane Angle in orthodontic diagnosis, classification, treatment planning and prognosis. Am J Orthod Oral Surg, St. Louis, v. 32, no. 4, p. 175-221, Apr. 1946

27. VIAZIS, A. D. Atlas de Ortodontia: princípios e aplicações clínicas. São Paulo: Ed. Santos, 1996. p. 110

28. ZAR, J. H. Biostatistical analysis. 3rd ed. New Jersey: PrenticeHall, 1996.

\footnotetext{
Endereço para correspondência

Carlos Alberto Gregório Cabrera

R. Lamenha Lins- 62, Curitiba/Pr

CEP: 80.450-020
}

cabrera@cabrera.com.br 